\title{
Low birth weight, preterm birth and small for gestational age association with adult depression: systematic review and meta-analysis
}

Christian Loret de Mola, Giovanny Vinícius Araújo de França, Luciana de Avila Quevedo and Bernardo Lessa Horta

\section{Background}

There is no consensus on the effects that low birth weight, premature birth and intrauterine growth have on later depression.

\begin{abstract}
Aims
To review systematically the evidence on the relationship of low birth weight, smallness for gestational age (SGA) and premature birth with adult depression.

\section{Method}

We searched the literature for original studies assessing the effect of low birth weight, premature birth and SGA on adult depression. Separate meta-analyses were carried out for each exposure using random and fixed effects models. We evaluated the contribution of methodological covariates to heterogeneity using meta-regression.
\end{abstract}

\section{Results}

We identified 14 studies evaluating low birth weight, 9 premature birth and 4 SGA. Low birth weight increased the odds of depression ( $\mathrm{OR}=1.39,95 \% \mathrm{Cl} 1.21-1.60)$. Premature birth and SGA were not associated with depression, but publication bias might have underestimated the effect of the former and only four studies evaluated SGA.

\section{Conclusions}

Low birth weight was associated with depression. Future studies evaluating premature birth and SGA are needed.

\section{Declaration of interest}

None.
The lifetime prevalence of depression in low- and high-income countries is $11.1 \%$ and $14.6 \%$ respectively. ${ }^{1}$ According to the World Health Organization (WHO), depression is the third leading cause of burden of disease, as measured by Disability Adjusted Lived Years, and in 2030 could be the first. ${ }^{2}$ Evidence suggests that exposures occurring during early years of life or even during pregnancy may have an important role in its development. ${ }^{3-7}$ Based on the thrifty phenotype hypothesis, ${ }^{8}$ this programming effect could be a consequence of poor nutrition during fetal life, ${ }^{5,7,9,10}$ causing an overstimulation of the hypothalamicpituitary-adrenal axis, which would increase fetal exposure to glucocorticoids and might produce lifelong effects on neurodevelopment, neurogenesis, hippocampal atrophy and lack of brain-derived neurotrophic factor. ${ }^{11,12}$ Most of the studies evaluating the programming effect of intrauterine growth on depression have used low birth weight as a proxy of intrauterine growth restriction. ${ }^{4,13-19}$ However, it is important to consider that birth weight is influenced by gestational age and intrauterine growth. According to the thrifty phenotype hypothesis, intrauterine growth retardation would programme the development of depression in adulthood, whereas gestational age would not be associated with depression through the mechanisms suggested by this hypothesis. It has also been suggested that the association between intrauterine growth retardation and depression in adulthood could be due to other mechanisms, such as maternal depression, intimate partner violence and socioeconomic position, which would be related to the occurrence of both low birth weight and depression in adulthood. ${ }^{20-30}$ Therefore, these conditions should be considered as possible confounders and adjusted in the analysis.

With respect to the association between low birth weight and depression, the evidence is divided. Some studies have reported an association; ${ }^{4,15,17,31-34}$ others have not. ${ }^{14,16,18,19,23,35,36}$ Few have assessed the independent effect of gestational age ${ }^{13,15,17,23,31,36,37}$ or intrauterine growth. ${ }^{23,35,36}$ A systematic review and meta-analysis by Wojcik et al reported a weak association (pooled odds ratio 1.15 , 95\% CI 1.00-1.32) between low birth weight and later depression. ${ }^{38}$ This pooled effect may have been overestimated by publication bias. Furthermore, their review included 'psychological distress' as one of the outcomes, comprising a broad spectrum of events such as changes in emotional status, discomfort, demoralisation and pessimism about the future, anguish and stress, self-depreciation or a 'maladaptive psychological functioning in the face of stressful life events. ${ }^{39,40}$ In spite of being a symptom of depression, psychological distress does not differentiate between depression and other non-affective disorders such as anxiety, and the inclusion of studies assessing psychological distress may have underestimated the association between birth weight and depression. Finally, as previously mentioned, low birth weight may be due to preterm birth, intrauterine growth retardation or a combination of both, and the review did not disentangle the effect of duration of gestation from that of intrauterine growth.

The aim of our systematic review and meta-analysis was to assess the relationship between low birth weight, SGA and premature birth, and depression in adulthood.

\section{Method}

We carried out a systematic search in PsycINFO (1967-2013), Medline (1950-2013), LILACS (1986-2013), the Cochrane Library and SciELO (1999-2013) databases (final search 10 September 2013); no limit was applied for language or year of publication. The following terms were used in the search: (Depressive OR Depression OR 'Depressive disorder' OR 'Mental Disorders' OR 'Mood Disorders') AND ('Birth Weight' OR 'Low-birth-weight' OR 'Very Low-birth-weight' OR 'Extremely Low-birth-weight' 
OR 'Fetal Weight' OR 'Fetal Growth Retardation' OR 'Premature Birth' OR 'Preterm Birth' OR 'Small for Gestational Age'). Included and excluded studies were collected following the guidance of the Preferred Reporting Items for Systematic Reviews and Meta-Analyses (PRISMA). ${ }^{41}$ We included original studies that assessed the risk of depression according to birth weight, gestational age or intrauterine growth among individuals over 18 years old, and in which depression was measured using self-rating scales or diagnostic interview. Studies that defined the outcome as psychological distress, common mental disorders and mood disorders, 'depression and/or anxiety' or any diagnosis that did not specifically identify the participant as having depression were not included. We also perused the reference lists of studies that were identified in the literature search.

\section{Study selection and data collection}

Eligibility assessment was performed independently by two reviewers (C.L. and G.V.F.). Initially, duplicate records were excluded, titles were screened and abstracts reviewed. Finally, full-text articles were examined (see Fig. 1). Two reviewers extracted the following data from the included articles: study design; methods used for measuring birth weight, premature birth, SGA and depression; age at assessment of depression; prevalence of the exposure and depression in the studied population; measure of association used; adjustment for confounders; if there was a clear description of exposure and outcome; sample size; categorisation of birth weight; studied population (hospital- or population-based); study direction (retrospective or prospective); and assessment of depression (interview or scale). Disagreements between reviewers were resolved by consensus or by a third expert (B.L.H.) when consensus was not achieved. We included only studies that reported the odds ratio (OR) for depression or that reported an estimate that could be transformed to $\mathrm{OR}$, such as prevalence ratio or $\beta$ from a logistic regression. If necessary we contacted the corresponding author for more information on the missing data that were needed for inclusion of the study. We contacted 13 authors for additional information; four responded, one of whom authored two studies, and provided additional estimates or handed us raw data to be analysed. ${ }^{14,15,36,42,43}$

\section{Statistical analysis}

Separate meta-analyses were performed for each of the exposures of interest - low birth weight, premature birth and SGA - using random and fixed effects models to pool the estimates. Heterogeneity among studies was evaluated using the $I^{2}$ statistic. As proposed by Higgins \& Thompson, an $I^{2}$ value below $31 \%$ was considered mild, ${ }^{44}$ and a fixed effects model was used. Studies presenting results stratified by gender were included twice, as independent studies. In addition, Herva et al reported estimates for different low-birth-weight categories so they were included independently. ${ }^{16}$ This did not alter the results, since each individual entered the analysis only once. Meta-regression was used to evaluate the contribution of several covariates to the heterogeneity among studies, ${ }^{45}$ estimating the $\tau^{2}$ and adjusted $R^{2}$ in each model. Funnel plots and Egger's test were used to evaluate the presence of publication bias. ${ }^{46}$ The analyses were performed using Stata version 11.2 for Windows.

\section{Results}

Initially we identified 1951 studies. After removing 413 duplicates we screened 1538 titles and abstracts, following which 15 articles were included in the meta-analysis (Fig. 1). Of these, 14 evaluated

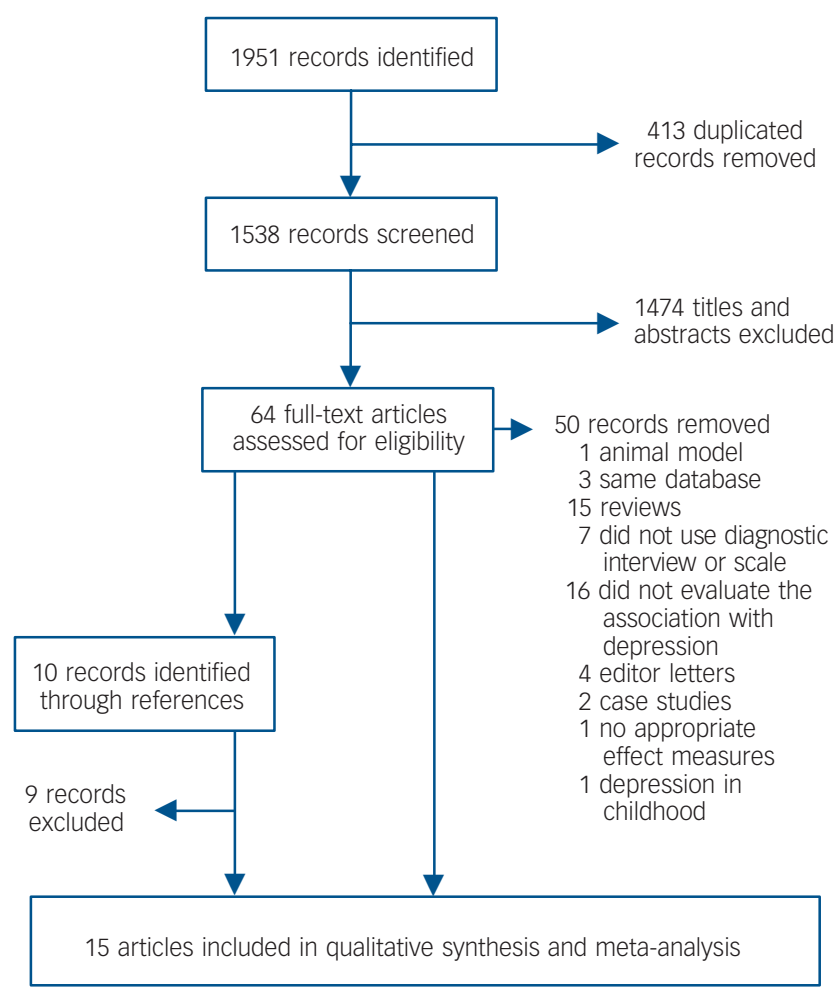

Fig. 1 Publication search.

the relationship between birth weight and depression in adulthood, ${ }^{4,13-17,19,23,33-36,42,43}$ of which four provided estimates on the odds of depression among those with very low birth weight; ${ }^{16,34-36}$ nine evaluated the relationship between preterm birth and depression; ${ }^{13-15,17,23,33,36,37,43}$ and four evaluated SGA and later depression. ${ }^{23,35,36,43}$ Table 1 summarises the studies included in our meta-analysis; specific details can be found in online Table DS1. Additional details of methodological quality and assessment are given in online Table DS2.

Ten studies were carried out in Europe, ${ }^{13-17,19,33,35,42,43}$ two in the USA, ${ }^{23,36}$ and three in Australia or New Zealand. ${ }^{4,34,37}$ In total, nine studies were population-based ${ }^{14-17,19,23,33,36,42}$ and six were hospital-based; ${ }^{4,13,34,35,37,43}$ ten had a prospective $\operatorname{design}^{4,13,14,16,19,23,34-37}$ and five studies were retrospective. ${ }^{15,17,33,42,43}$ All retrospective and five prospective studies $^{4,13,14,34,35}$ used data from birth records; four measured birth weight, ${ }^{16,19,23,36}$ and one used maternal recall. ${ }^{42}$ With respect to the assessment of depression, four studies used a psychiatric interview, ${ }^{13,15,36,43}$ three used the Beck Depression Inventory (BDI), ${ }^{33,35,37}$ two used the Center for Epidemiologic Studies Depression scale (CES-D), ${ }^{4,33}$ and the remaining ten studies used other scales. ${ }^{47-55}$ With respect to the age at assessment of depression, four studies evaluated depression among individuals older than 40 years. $^{15,19,33,42}$

\section{Birth weight}

We identified 14 studies providing 21 estimates of the relationship between birth weight and depression in adulthood. ${ }^{4,13-17,19,23,33-36,42,43}$ Thirteen estimates suggested higher odds of depression among those with low birth weight, but for six of these the confidence interval did not include the reference, ${ }^{4,15,17,33,34,42}$ whereas eight reported a negative association with a confidence interval 


\begin{tabular}{|c|c|c|c|c|c|}
\hline First author (year) & Sample size & Exposure & Depression scale & Adjustment & Association \\
\hline Alati $(2007)^{4}$ & 3493 & BW & CES-D & Sociodemographic GA & Yes \\
\hline Batstra $(2006)^{13}$ & 258 & BW/GA & CIDI & Sociodemographic & No \\
\hline Dalziel $(2007)^{37}$ & 192 & GA & BDI-II & Not adjusted & No \\
\hline Fan $(2001)^{23}$ & 1824 & BW/GA/SGA & GHQ-28 & Sociodemographic & Yes GA \\
\hline Gale $(2004)^{14}$ & 8292 & BW/GA & Malaise Inventory & Sociodemographic GA/BW & No \\
\hline Gale $(2011)^{42}$ & $465 / 3211$ & BW & HADS & Sociodemographic & Yes \\
\hline Gudmundsson (2011) ${ }^{15}$ & 715 & $\mathrm{BW} / \mathrm{GA}$ & Interview & Sociodemographic GA/BW & Yes \\
\hline Herva $(2008)^{16}$ & 8339 & BW & HSCL-25 & Sociodemographic GA & No \\
\hline Mallen $(2008)^{17}$ & 521 & BW/GA & HADS & Sociodemographic & Yes BW \\
\hline Preti $(2000)^{43}$ & 60 & BW/GA/SGA & Interview & Not adjusted & No \\
\hline Raikkonen $(2007)^{33}$ & 1371 & BW/GA & BDI/CES-D & Sociodemographic GA & Yes \\
\hline Raikkonen $(2008)^{35}$ & 234 & BW/SGA & $\mathrm{BDI}$ & Sociodemographic & No \\
\hline Thompson $(2001)^{19}$ & 810 & BW & GDS/GMS & Sociodemographic & No \\
\hline Vasiliadis $(2008)^{36}$ & 1101 & BW/GA/SGA & DIS & Sociodemographic & No \\
\hline Westrupp (2011) $)^{34}$ & 149 & BW & SCL-90-R & Not adjusted & Yes \\
\hline
\end{tabular}

including the reference. The fixed-effect pooled OR was 1.39 (95\% CI 1.21-1.60), $I^{2}=24.5 \%$ (Fig. 2(a)).

Table 2 shows that the pooled effect was lower among studies that provided separate estimates for men $(\mathrm{OR}=1.12,95 \% \mathrm{CI}$ $0.82-1.54)$, whereas those providing estimates for women only had a pooled effect of 1.30 (95\% CI 1.06-1.59) and those that included both genders reported the highest pooled effect $(\mathrm{OR}=1.75,95 \%$ CI $1.38-2.23)$, but these differences were not statistically significant. Pooled effects were heterogeneous, depending on the birth-weight categories being compared. Studies that compared the odds of depression in groups with low birth weight $(\leqslant 2.5 \mathrm{~kg}) v$. normal birth weight $(>2.5 \mathrm{~kg})$ provided the highest pooled effect, and the lowest was observed among studies comparing birth weights of $\leqslant 2.5 \mathrm{~kg} v .>3.5 \mathrm{~kg}$ and those evaluating very low birth weights $(\leqslant 2.0 \mathrm{~kg})$. Studies that evaluated individuals younger than 40 years reported a smaller effect of low birth weight $(\mathrm{OR}=1.24,95 \%$ CI $1.05-1.47)$ than those evaluating individuals older than 40 years $(\mathrm{OR}=1.75$, 95\% CI 1.37-2.22). Studies that did not control for possible confounders reported higher odds of depression among lowbirth-weight individuals than those reporting adjusted estimates, but the effect of low birth weight was statistically significant even among studies that controlled for sociodemographic variables and gestational age (pooled $\mathrm{OR}=1.35,95 \%$ CI 1.15-1.60). Retrospective studies reported a higher odds ratio than those that used a prospective design. Sample size did not modify the estimated effect of birth weight on depression (Table 2). In univariate meta-regression models, birth-weight categorisation, study design, age at assessment of depression and exposure measure showed a $\tau^{2}$ of zero, i.e. each of these variables explained the total heterogeneity among studies (Table 2).

Table 3 shows that in the multivariate meta-regression, even after adjusting for exposure measure, age at assessment of depression, sample size and adjustment for confounders, the variables birth-weight category and study design maintained their association with heterogeneity among studies. Study design and birth-weight categorisation clearly lost their effects only when adjusted for each other, probably because five of the six studies with a retrospective design also compared low birth weight $(\leqslant 2.5 \mathrm{~kg}$ ) with birth weights over $2.5 \mathrm{~kg}$, so no further differentiation was possible between these two covariates. Funnel-plot and Egger's tests $(P=0.683)$ showed no evidence of publication bias (Fig. 3). In addition, five studies included in the meta-analysis looked into the linear effect of birth weight, reporting estimates for continuous measures of birth weight, but none found a relation with adult depression (data not shown). ${ }^{4,13,15,33,42}$

\section{Premature birth}

We obtained eight estimates, from seven articles, on the relationship between premature birth and depression in adulthood. Only two estimates showed a positive association between premature birth and depression; the other six had confidence intervals including the reference. The random effects pooled estimate obtained was 1.08 (95\% CI $0.77-1.52), I^{2}=47.8 \%$ (see Fig. 2(b)). The funnel plot was asymmetric, suggesting that small studies reporting higher odds of depression among those with preterm birth were missing (see Fig. 3). In the meta-regression we observed that sample size and sample population explained $66 \%$ and $100 \%$ of the heterogeneity among studies, respectively. Table 2 shows that small studies $(n<500)$ and hospital-based studies, which were the same, reported a protective effect of preterm birth $(\mathrm{OR}=0.58,95 \% \mathrm{CI} 0.32-1.06)$, whereas among studies with a sample size of 1000 individuals or more the pooled effect was 1.70 (95\% CI $0.83-3.48$ ). By pooling the studies with more than 500 individuals, we observed a pooled OR of 1.31 (95\% CI 0.96-1.79). Furthermore, two studies reported continuous estimations of gestational age and depression during adulthood. Raikkonen et al found that for each increase of 1 day in gestational age there was a decrease in the odds of depression $(\mathrm{OR}=0.97,95 \%$ CI $0.95-0.99),{ }^{33}$ whereas Gudmundsson et al found that shorter gestational time (weeks) increased the odds $(\mathrm{OR}=1.11,95 \%$ CI $1.01-1.22) .{ }^{15}$

\section{Small for gestational age}

Four studies, providing five estimates, evaluated the association between SGA and depression in adulthood. The pooled random effect OR was 1.14 (95\% CI 0.64-2.03), $I^{2}=49.7 \%$ (Fig. 2(c)). Because of the small number of studies included in this metaanalysis we did not perform a meta-regression or generate a funnel plot. 
Alati et al $(2007)^{4}$ (A) Batstra et al (2006) $)^{13}(\mathrm{~A})$ Fan \& Eaton (2001) ${ }^{23}$ (A) Gale \& Martyn (2004) $)^{14}(\mathrm{M})$ Gale \& Martyn (2004) $)^{14}(F)$ Gale et al (2011) ${ }^{42}$ (CaPS, M) Gale et al (2011) $)^{42}$ (HCS, A) Gudmundsson et al (2011) $)^{15}(\mathrm{~F})$ Herva et al $(2008)^{16}(\mathrm{M})^{\mathrm{a}}$ Herva et al $(2008)^{16}(\mathrm{~F})^{\mathrm{a}}$ Herva et al $(2008)^{16}(\mathrm{M})^{\mathrm{b}}$ Herva et al $(2008)^{16}(\mathrm{~F})^{\mathrm{b}}$ Mallen et al (2008) ${ }^{17}$ (A) Preti et al $(2000)^{43}$ (A) Raikkonen et al (2007) $)^{33}$ (A) Raikkonen et al (2008) $)^{35}$ (A) Thompson et al (2001) ${ }^{19}$ (M) Thompson et al (2001) $)^{19}$ (F) vasiliadis et al (2008) ${ }^{36}(\mathrm{M})$ Vasiliadis et al (2008) ${ }^{36}(\mathrm{~F})$ Westrupp et al (2011) $)^{34}$ (A) Overall $\left(I^{2}=24.5 \%, P=0.15\right)$

$1.55(1.03,2.34)$

$1.46(0.55,3.83) \quad 2.05$

$1.65(0.58,4.68) \quad 1.77$

$1.10(0.71,1.71) \quad 9.76$

$1.30(0.89,1.89) \quad 13.77$

$1.42(0.47,4.27) \quad 1.59$

$2.07(1.17,3.68) \quad 5.83$

$1.63(1.20,2.22) \quad 20.31$

$0.91(0.44,1.87) \quad 3.70$

$0.97(0.56,1.67) \quad 6.51$

$0.86(0.20,3.73) \quad 0.89$

$0.90(0.34,2.37) \quad 2.05$

$2.88(1.32,6.27) \quad 3.18$

$4.46(0.47,42.41) \quad 0.38$

$3.10(1.30,7.40) \quad 2.54$

$0.80(0.41,1.55) \quad 4.40$

$3.00(0.87,10.30) \quad 1.26$

$0.70(0.23,2.16) \quad 1.52$

$0.97(0.41,2.31) \quad 2.56$

$0.98(0.48,2.00) \quad 3.80$

$5.17(1.17,22.92) \quad 0.87$

$1.39(1.21,1.60) \quad 100.00$

(b)

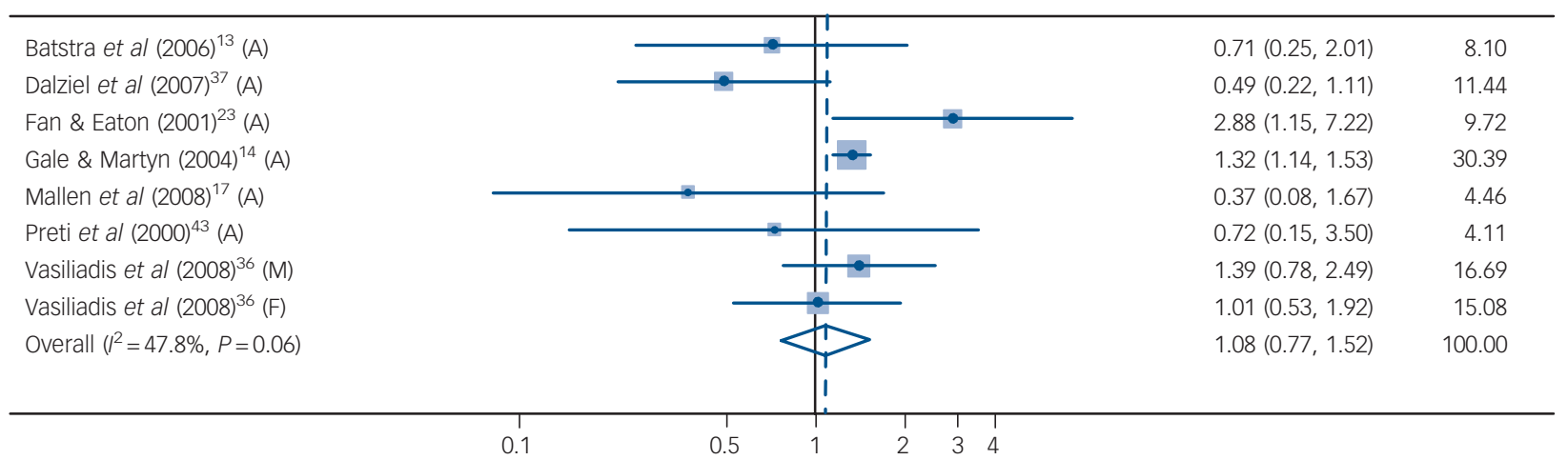

(c)

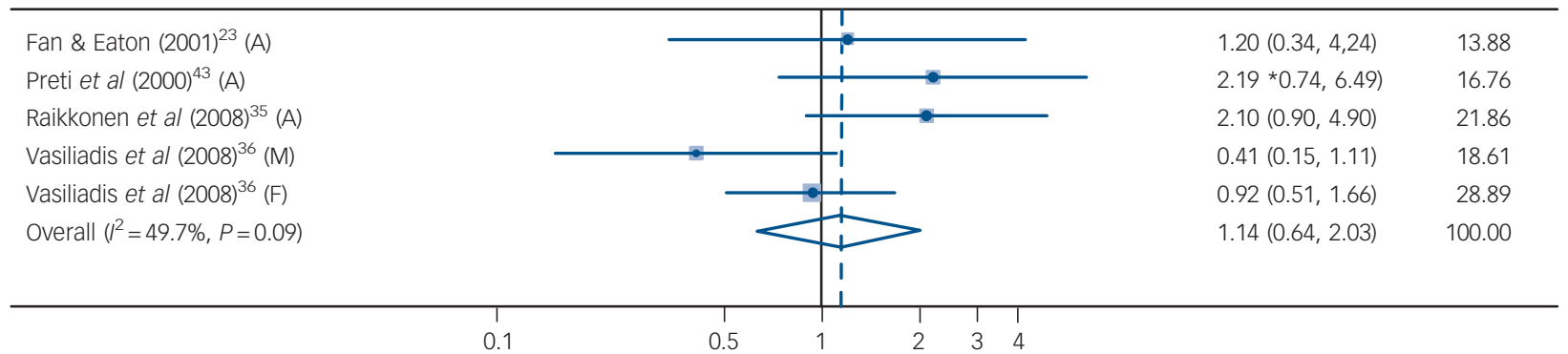

Fig. 2 (a) Fixed effects meta-analysis of studies evaluating low birth weight and depression during adulthood (CaPS, Caerphilly Prospective Study; HCS, Hertfordshire Cohort Study). (b) Random effects meta-analysis of studies evaluating premature birth and depression during adulthood. Weights are from random effects analysis. (c) Random effects meta-analysis of studies evaluating smallness for gestational age and depression during adulthood. Weights are from random effects analysis. A, estimate in men and women; $M$, estimate for men; F, estimate for women. 
Table 2 Univariate meta-regression and pooled odds ratio estimates of birth weight and premature birth on depression

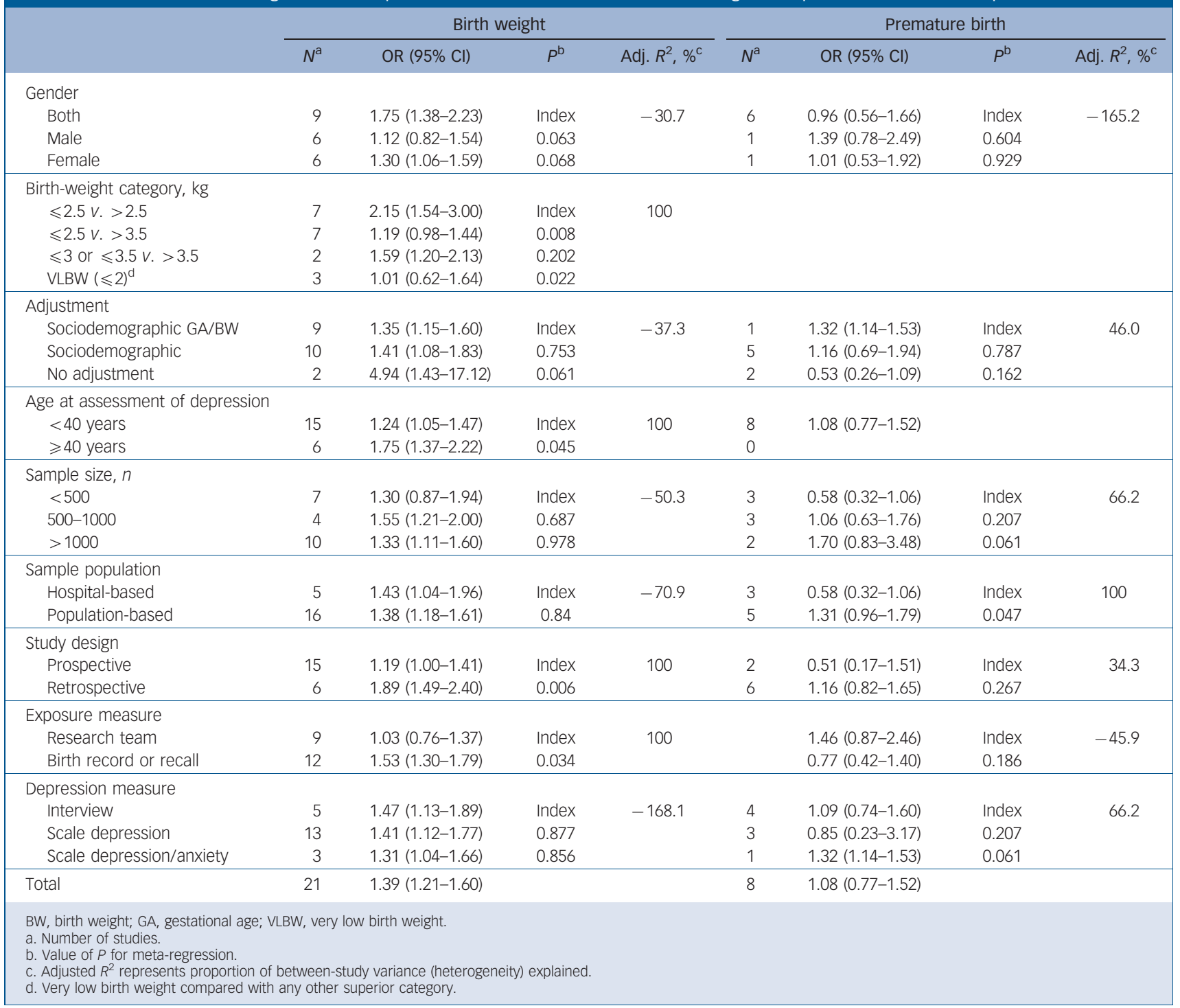

Table 3 Multivariate meta-regression of birth-weight category and study design on other methodological covariates, in studies evaluating low birth weight

\begin{tabular}{|c|c|c|c|c|}
\hline & \multicolumn{4}{|c|}{ Adjustment $^{\mathrm{a}}$} \\
\hline & $\begin{array}{l}\text { Exposure } \\
\text { measure }\end{array}$ & $\begin{array}{l}\text { Age at assessment } \\
\text { of depression }\end{array}$ & $\begin{array}{l}\text { Sample size and adjustment } \\
\text { for confounders }\end{array}$ & $\begin{array}{l}\text { Mutually } \\
\text { adjusted }\end{array}$ \\
\hline \multicolumn{5}{|l|}{ Birth-weight category, kg } \\
\hline$\leqslant 2.5 \mathrm{v} .>2.5$ & Index & Index & Index & Index \\
\hline$\leqslant 2.5 \mathrm{v} .>3.5$ & 0.017 & 0.052 & 0.032 & 0.276 \\
\hline$\leqslant 3$ or $\leqslant 3.5 \mathrm{v} .>3.5$ & 0.211 & 0.273 & 0.697 & 0.165 \\
\hline $\operatorname{VLBW}(\leqslant 2)^{\mathrm{b}}$ & 0.039 & 0.054 & 0.075 & 0.203 \\
\hline \multicolumn{5}{|l|}{ Study design } \\
\hline Prospective & Index & Index & Index & Index \\
\hline Retrospective & 0.031 & 0.038 & 0.004 & 0.313 \\
\hline
\end{tabular}

\section{Discussion}

We observed a positive association between low birth weight and depression in adulthood, whereas for preterm birth no association was observed. The small number of studies assessing the effect of SGA precluded any conclusion being drawn. For low birth weight, the funnel plot was symmetrical and the association was not modified by sample size, suggesting that the observed association was not due to publication bias. The stratified analysis showed that retrospective studies and those comparing individuals whose birth weights were $\leqslant 2.5 \mathrm{~kg} v$. $>2.5 \mathrm{~kg}$ presented higher pooled effects, and these two covariates explained all the heterogeneity among studies. 
(a)

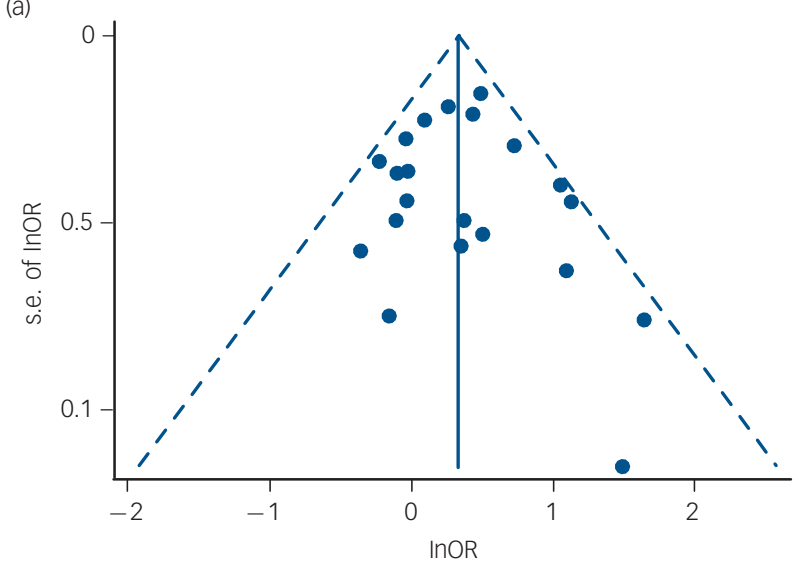

(b)

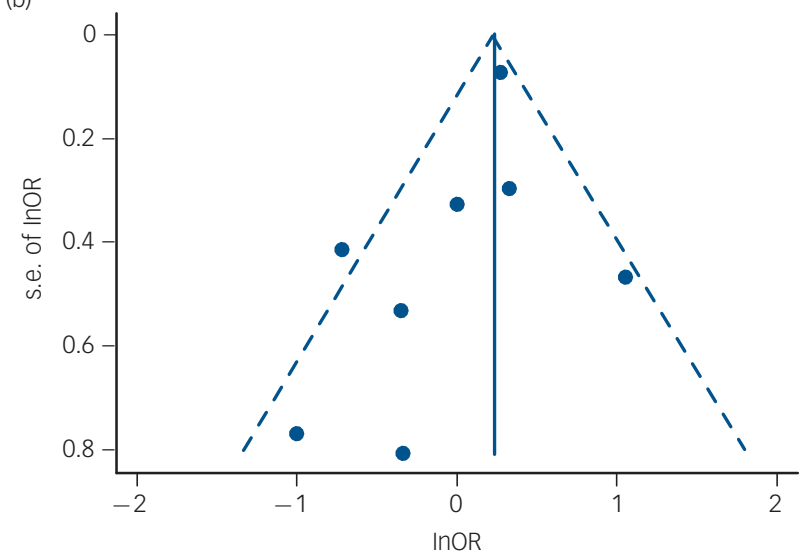

Fig. 3 Funnel plots: (a) estimates from studies evaluating low

birth weight; (b) estimates from studies evaluating premature birth. InOR, natural logarithm of the odds ratio, s.e., standard error.

Converse to the notion that the comparison among the most extreme categories would increase the magnitude of the association, in our meta-analysis the highest pooled effect was observed for studies comparing low birth weight $(\leqslant 2.5 \mathrm{~kg})$ with normal birth weight $(>2.5 \mathrm{~kg}$ ). Adjustment for age at assessment of depression did not change the differences in pooled effects of birth categorisation. However, the association was lost after adjusting for study design; the pooled odds ratios among studies that compared birth weights of $\leqslant 2.5 \mathrm{~kg} v .>3.5 \mathrm{~kg}$ changed from 0.55 ( $95 \%$ CI $0.36-0.84$ ) to 0.71 (95\% CI $0.38-1.39$ ). This suggests that retrospective design could be responsible for the differences in the pooled estimates of birth categorisation. Another explanation could be the fact that higher birth weight might also increase the chances of later mental disease, ${ }^{16,56-58}$ which would explain why continuous birth weight does not show a linear association with adult depression, but studies showing this ' $U$ ' or 'J' association specifically for depression are scarce. Furthermore, in spite of not explaining the heterogeneity among studies, the stratified analysis showed that studies that controlled for confounding by socioeconomic and demographic variables reported a smaller odds ratio than studies that reported crude estimates. Because low birth weight and depression are related to socioeconomic position and this relationship depends on the tool used to assess it, ${ }^{22,59,60}$ confounding by socioeconomic position should overestimate the measure of association, as we observed. Therefore future studies should appropriately address this issue on confounding.

Contrary to the findings of Wojcik et al in a previous metaanalysis, ${ }^{38}$ we observed that low birth weight increased the odds of depression in adulthood. Our controversial findings could be because we did not include studies that evaluated psychological distress ${ }^{56,61-67}$ and included only studies among adults. On the other hand, a meta-analysis by Burnett et al found that children born preterm and with low birth weight had increased odds of later anxiety/depression, ${ }^{68}$ but once again in this review depression was not individually assessed, and also Burnett et al evaluated individuals in the age range 10-25 years.

\section{Strengths and limitations}

We did not search for studies in other databases such as EMBASE, but we do not believe this would have altered our results. Wojcik et al searched EMBASE and identified the same studies (up to 2011) that were identified in our search. ${ }^{38}$ Furthermore, it is unlikely that the exclusion of three studies that did not provide information on the measure of association to be included in the meta-analysis biased the pooled estimate away from the null. ${ }^{69-71}$ Sample sizes in these studies were small $(n<500)$ and they reported an association between birth weight and depression in the same direction we have reported. Intimate partner violence, maternal depression during pregnancy and mother's education and wealth could also be associated with poor perinatal outcomes and depression in adulthood, involving different pathways to the one proposed. ${ }^{21-30}$ In our meta-analysis, most of the studies reported estimates that were adjusted for some of these possible confounders, such as sociodemographic variables and maternal depression. On the other hand, none of the included studies controlled for intimate partner violence. Therefore, we cannot rule out that the observed association was due to residual confounding by intimate partner violence.

With respect to the assessment of the outcome, only four of the 15 included studies used diagnostic interviews for the assessment of depression, ${ }^{13,15,36,43}$ which is considered the gold standard for depression diagnosis. Nine used screening scales, the BDI and the Hospital Anxiety and Depression Scale subscale for depression, ${ }^{48,55}$ that are able to differentiate between depression and anxiety, ${ }^{13,16,19,23,33-35,37,42}$ or used a subscale for depression or a semistructured interview to confirm depression. ${ }^{16,19,23,34}$ The remaining two studies used screening scales (the CES-D and Malaise Inventory) that are unable to distinguish between depression and anxiety. ${ }^{4,14}$ The use of screening scales to assess the occurrence of depression may have introduced a classification error. Nevertheless, it is important to stress that such bias is non-differential, so would tend to underestimate any association. On the other hand the assessment of the outcome was not a source of heterogeneity, as shown in Table 2. Therefore, we believe that the pooled estimates were not biased by the use of screening scales to assess depression.

Our meta-analysis had the strength of including studies of not only low birth weight but also premature birth and SGA, trying to disentangle the complex association between birth conditions and later disease. Furthermore, using meta-regression, we identified possible sources of heterogeneity; study design and birth-weight categorisation explained the heterogeneity among studies that evaluated the relationship between birth weight and depression.

\section{Associations with depression}

Birth weight is mainly determined by the infant's gestational age and intrauterine growth, therefore the biological association between low birth weight and later depression observed in this meta-analysis should be explained by one of these two factors. Premature birth showed an estimate close to the reference. Nevertheless, publication bias may have underestimated this association, 
as the pooled estimate among small studies was in the opposite direction to that observed among studies with a sample size greater than 1000, and when we estimated the pooled estimate among studies that evaluated more than 500 individuals we observed a pooled OR of 1.31 (95\% CI $0.96-1.79$ ), which just includes the reference. In addition, two studies found an inverse relationship between continuous gestational age and the odds of later depression. ${ }^{15,33}$ Consequently, we cannot rule out that premature birth might be associated with adult depression, and more studies evaluating this relationship are necessary. Nonetheless, we should point out that the isolated effect of gestational age is not related to the thrifty phenotype hypothesis and could be part of other mechanisms, such as the ones proposed earlier. Few studies evaluated SGA and their results were clearly heterogeneous, with some studies reporting ORs higher than $2.0,{ }^{35,43}$ whereas Vasiliadis et al observed a protective association with $\mathrm{SGA} ;{ }^{36}$ however, for all included studies the confidence interval included the unity. Therefore, we were unable to draw a conclusion on the association between depression and SGA.

\section{Future research}

On the basis of these findings, we believe that special attention should be focused on children of low birth weight, as they may be a high-risk group for future development of depression. In addition, more research is needed on the effect of premature birth and intrauterine growth on depression in adulthood. New studies should use a prospective design, and diagnosis of depression should be based on diagnostic interview or screening scales that are clearly able to differentiate depression from anxiety. Furthermore, these studies should also control the estimates for sociodemographic, biological and other variables such as intimate partner violence and maternal depression.

Christian Loret de Mola, MD, MSC, Giovanny Vinícius Araújo de França, MSC, Postgraduate Programme in Epidemiology, Federal University of Pelotas; Luciana de Avila Quevedo, PhD, Postgraduate Programme in Health and Behaviour, Catholic University of Pelotas; Bernardo Lessa Horta, MD, PhD, Postgraduate Programme in Epidemiology, Federal University of Pelotas, Brazil

Correspondence: Dr Christian Loret de Mola, Postgraduate Programme in Epidemiology, Federal University of Pelotas, Rua Marechal Deodoro, 11603 Piso, Pelotas 96020-220, Brazil. Email: chlmz@yahoo.com

First received 19 Sep 2013, final revision 10 Apr 2014, accepted 19 May 2014

\section{Funding}

The research was supported by Fundação de Amparo à Pesquisa do Estado do Rio Grande do Sul, Programa Pesquisador Gaúcho, Processo 11/1815-8.

\section{Acknowledgements}

We thank all the authors of the included papers who kindly gave us access to their databases or provided new estimates or additional information concerning their research.

\section{References}

1 Bromet E, Andrade LH, Hwang I, Sampson NA, Alonso J, de Girolamo G, et al. Cross-national epidemiology of DSM-IV major depressive episode. BMC Med 2011; 9: 90

2 World Health Organization. The Global Burden of Disease: 2004 Update. WHO, 2008.

3 Brown GW, Harris TO. Depression and the serotonin transporter 5-HTTLPR polymorphism: a review and a hypothesis concerning gene-environment interaction. J Affect Disord 2008; 111: 1-12.

4 Alati R, Lawlor DA, Mamun AA, Williams GM, Najman JM, O'Callaghan M, et al. Is there a fetal origin of depression? Evidence from the Mater
University Study of Pregnancy and its outcomes. Am J Epidemiol 2007; 165: 575-82.

5 Brown AS, Susser ES, Lin SP, Neugebauer R, Gorman JM. Increased risk of affective disorders in males after second trimester prenatal exposure to the Dutch hunger winter of 1944-45. Br J Psychiatry 1995; 166: 601-6.

6 Brown AS, van OS J, Driessens C, Hoek HW, Susser ES. Further evidence of relation between prenatal famine and major affective disorder. Am J Psychiatry 2000; 157: 190-5.

7 Schlotz W, Phillips DI. Fetal origins of mental health: evidence and mechanisms. Brain Behav Immun 2009; 23: 905-16.

8 Hales CN, Barker DJ. The thrifty phenotype hypothesis. Br Med Bull 2001; 60: 5-20.

9 Stein $A D$, Pierik FH, Verrips GH, Susser ES, Lumey LH. Maternal exposure to the Dutch famine before conception and during pregnancy: quality of life and depressive symptoms in adult offspring. Epidemiology 2009; 20: 909-15.

10 Casper RC. Nutrients, neurodevelopment, and mood. Curr Psychiatry Rep 2004; 6: 425-9.

11 Kapoor A, Dunn E, Kostaki A, Andrews MH, Matthews SG. Fetal programming of hypothalamo-pituitary-adrenal function: prenatal stress and glucocorticoids. J Physiol 2006; 572: 31-44.

12 Belmaker RH, Agam G. Major depressive disorder. N Engl J Med 2008; 358 55-68.

13 Batstra L, Neeleman J, Elsinga C, Hadders-Algra M. Psychiatric morbidity is related to a chain of prenatal and perinatal adversities. Early Hum Dev 2006; 82: 721-9.

14 Gale $\mathrm{CR}$, Martyn CN. Birth weight and later risk of depression in a national birth cohort. Br J Psychiatry 2004; 184: 28-33.

15 Gudmundsson $\mathrm{P}$, Andersson S, Gustafson D, Waern M, Ostling S, Hallstrom T, et al. Depression in Swedish women: relationship to factors at birth. Eur $J$ Epidemiol 2011; 26: 55-60.

16 Herva A, Pouta A, Hakko H, Läksy K, Joukamaa M, Veijola J. Birth measures and depression at age 31 years: the Northern Finland 1966 Birth Cohort Study. Psychiatry Res 2008; 160: 263-70.

17 Mallen C, Mottram S, Thomas E. Birth factors and common mental health problems in young adults: a population-based study in North Staffordshire. Soc Psychiatry Psychiatr Epidemiol 2008; 43: 325-30.

18 Nomura Y, Wickramaratne PJ, Pilowsky DJ, Newcorn JH, Bruder-Costello B, Davey $C$, et al. Low birth weight and risk of affective disorders and selected medical illness in offspring at high and low risk for depression. Compr Psychiatry 2007; 48: 470-8.

19 Thompson C, Syddall H, Rodin I, Osmond C, Barker DJP. Birth weight and the risk of depressive disorder in late life. Br J Psychiatry 2001; 179: 450-5.

20 Kinsella MT, Monk C. Impact of maternal stress, depression and anxiety on fetal neurobehavioral development. Clin Obstet Gynecol 2009; 52: 425-40.

21 Grigoriadis S, VonderPorten EH, Mamisashvili L, Tomlinson G, Dennis CL, Koren $\mathrm{G}$, et al. The impact of maternal depression during pregnancy on perinatal outcomes: a systematic review and meta-analysis. J Clin Psychiatry 2013; 74: e321-41.

22 Eaton WW, Muntaner C, Bovasso G, Smith C. Socioeconomic status and depressive syndrome: the role of inter- and intra-generational mobility, government assistance, and work environment. J Health Soc Behav 2001; 42 277-94.

23 Fan AP, Eaton WW. Longitudinal study assessing the joint effects of socioeconomic status and birth risks on adult emotional and nervous conditions. Br J Psychiatry 2001; 178 (suppl 40): s78-s83.

24 Gilman SE, Kawachi I, Fitzmaurice GM, Buka SL. Socioeconomic status in childhood and the lifetime risk of major depression. Int J Epidemiol 2002; 31: 359-67.

25 Matijasevich A, Santos IS, Menezes AM, Barros AJ, Gigante DP, Horta BL, et al. Trends in socioeconomic inequalities in anthropometric status in a population undergoing the nutritional transition: data from 1982, 1993 and 2004 Pelotas Birth Cohort studies. BMC Publ Health 2012; 12: 511.

26 Caspi A, Sugden K, Moffitt TE, Taylor A, Craig IW, Harrington H, et al. Influence of life stress on depression: moderation by a polymorphism in the 5-HTT gene. Science 2003; 301: 386-9.

27 Pearson RM, Evans J, Kounali D, Lewis G, Heron J, Ramchandani PG, et al. Maternal depression during pregnancy and the postnatal period: risks and possible mechanisms for offspring depression at age 18 years. JAMA 2013; 70: $1312-9$.

28 Lovejoy MC, Graczyk PA, O'Hare E, Neuman G. Maternal depression and parenting behavior: a meta-analytic review. Clin Psychol Rev 2000; 20 : 561-92.

29 Boy A, Salihu HM. Intimate partner violence and birth outcomes: a systematic review. Int J Fertil Women's Med 2004; 49: 159-64. 
30 Campbell JC. Health consequences of intimate partner violence. Lancet 2002 359: 1331-6.

31 Nomura Y, Brooks-Gunn J, Davey C, Ham J, Fifer WP. The role of perinatal problems in risk of co-morbid psychiatric and medical disorders in adulthood. Psychol Med 2007; 37: 1323-34.

32 Paile-Hyvarinen $M$, Raikkonen $K$, Forsen $T$, Kajantie $E$, Yliharsila $H$, Salonen MK, et al. Depression and its association with diabetes, cardiovascular disease, and birth weight. Ann Med 2007; 39: 634-40.

33 Raikkonen K, Pesonen AK, Kajantie E, Heinonen K, Forsen T, Phillips DW, et al. Length of gestation and depressive symptoms at age 60 years. Br J Psychiatry 2007; 190: 469-74.

34 Westrupp EM, Northam E, Doyle LW, Callanan C, Anderson PJ. Adult psychiatric outcomes of very low birth weight survivors. Aust $\mathrm{N} \mathrm{Z} \mathrm{J}$ Psychiatry 2011; 45: 1069-77.

35 Raikkonen K, Pesonen AK, Heinonen K, Kajantie E, Hovi P, Jarvenpaa AL, et al. Depression in young adults with very low birth weight: the Helsinki study of very low-birth-weight adults. Arch Gen Psychiatry 2008; 65: 290-6.

36 Vasiliadis HM, Gilman SE, Buka SL. Fetal growth restriction and the development of major depression. Acta Psychiatr Scand 2008; 117: 306-12.

37 Dalziel SR, Lim VK, Lambert A, McCarthy D, Parag V, Rodgers A, et al. Psychological functioning and health-related quality of life in adulthood after preterm birth. Dev Med Child Neurol 2007; 49: 597-602.

38 Wojcik W, Lee W, Colman I, Hardy R, Hotopf M. Foetal origins of depression? A systematic review and meta-analysis of low birth weight and later depression. Psychol Med 2013; 43: 1-12.

39 Ridner SH. Psychological distress: concept analysis. J Adv Nurs 2004; 45 536-45.

40 Masse R. Qualitative and quantitative analyses of psychological distress: methodological complementarity and ontological incommensurability. Qual Health Res 2000; 10: 411-23.

41 Moher D, Liberati A, Tetzlaff J, Altman DG, Group P. Preferred reporting items for systematic reviews and meta-analyses: the PRISMA statement. PLOS Med 2009; 6: e1000097.

42 Gale CR, Sayer AA, Cooper C, Dennison EM, Starr JM, Whalley $\sqcup$, et al Factors associated with symptoms of anxiety and depression in five cohorts of community-based older people: the HALCyon (Healthy Ageing across the Life Course) programme. Psychol Med 2011; 41: 2057-73.

43 Preti A, Cardascia L, Zen T, Pellizzari P, Marchetti M, Favaretto G, et al. Obstetric complications in patients with depression - a population-based case-control study. J Affect Disord 2000; 61: 101-6.

44 Higgins JP, Thompson SG. Quantifying heterogeneity in a meta-analysis. Stat Med 2002; 21: 1539-58.

45 Berkey CS, Hoaglin DC, Mosteller F, Colditz GA. A random-effects regression model for meta-analysis. Stat Med 1995; 14: 395-411.

46 Egger M, Davey Smith G, Schneider M, Minder C. Bias in meta-analysis detected by a simple, graphical test. BMJ 1997; 315: 629-34.

47 Almeida OP, Almeida SA. Short versions of the geriatric depression scale: a study of their validity for the diagnosis of a major depressive episode according to ICD-10 and DSM-IV. Int J Geriatr Psychiatry 1999; 14: 858-65.

48 Beck AT, Steer RA, Carbin MG. Psychometric properties of the Beck Depression Inventory: twenty-five years of evaluation. Clin Psychol Rev 1988 8: $77-100$.

49 Derogatis LR, Lipman RS, Covi L. SCL-90: an outpatient psychiatric rating scale - preliminary report. Psychopharmacol Bull 1973; 9: 13-28.

50 Goldberg DP, Hillier VF. A scaled version of the General Health Questionnaire. Psychol Med 1979; 9: 139-45.

51 McWilliam C, Copeland JR, Dewey ME, Wood N. The Geriatric Mental State Examination as a case-finding instrument in the community. $\mathrm{Br} J$ Psychiatry 1988; 152: 205-8.
52 Radloff LS. The CES-D Scale: a self-report depression scale for research in the general population. Appl Psychol Meas 1977; 1: 385-401.

53 Rutter M, Tizard J, Whitmore K. Education, Health and Behaviour. Longman, 1970.

54 Winokur A, Winokur DF, Rickels K, Cox DS. Symptoms of emotional distress in a family planning service: stability over a four-week period. $\mathrm{Br} J$ Psychiatry 1984; 144: 395-9.

55 Zigmond AS, Snaith RP. The hospital anxiety and depression scale. Acta Psychiatr Scand 1983; 67: 361-70.

56 Colman I, Ploubidis GB, Wadsworth ME, Jones PB, Croudace TJ. A longitudinal typology of symptoms of depression and anxiety over the life course. Biol Psychiatry 2007; 62: 1265-71.

57 Cheung YB, Khoo KS, Karlberg J, Machin D. Association between psychological symptoms in adults and growth in early life: Iongitudinal follow up study. BMJ 2002; 325: 749.

58 Van Lieshout RJ, Boyle MH. Is bigger better? Macrosomia and psychopathology later in life. Obes Rev 2011; 12: e405-11.

59 Melchior M, Chastang JF, Head J, Goldberg M, Zins M, Nabi H, et al. Socioeconomic position predicts long-term depression trajectory: a 13-year follow-up of the GAZEL cohort study. Mol Psychiatry 2013; 18: 112-21.

60 Parker JD, Schoendorf KC, Kiely JL. Associations between measures of socioeconomic status and low birth weight, small for gestational age, and premature delivery in the United States. Ann Epidemiol 1994; 4: 271-8.

61 Berle JO, Mykletun A, Daltveit AK, Rasmussen S, Dahl AA. Outcomes in adulthood for children with foetal growth retardation. A linkage study from the Nord-Trondelag Health Study (HUNT) and the Medical Birth Registry of Norway. Acta Psychiatr Scand 2006; 113: 501-9.

62 Elgen I, Sommerfelt K, Markestad T. Population based, controlled study of behavioural problems and psychiatric disorders in low birthweight children at 11 years of age. Arch Dis Child Fetal Neonatal Ed 2002; 87: F128-32.

63 Haavind S, Bergin I, Brubakk AM. [Mental health, school and leisure time of adolescents born 'small for gestational age']. Tidsskr Nor Laegeforen 2007; 127: 1933-7.

64 Hack M, Youngstrom EA, Cartar L, Schluchter M, Taylor HG, Flannery D, et al. Behavioral outcomes and evidence of psychopathology among very low birth weight infants at age 20 years. Pediatrics 2004; 114: 932-40.

65 Inskip HM, Dunn N, Godfrey KM, Cooper C, Kendrick T. Is birth weight associated with risk of depressive symptoms in young women? Evidence from the Southampton Women's Survey. Am J Epidemiol 2008; 167: 164-8.

66 Patton GC, Coffey C, Carlin JB, Olsson CA, Morley R. Prematurity at birth and adolescent depressive disorder. Br J Psychiatry 2004; 184: 446-7.

67 Wiles NJ, Peters TJ, Leon DA, Lewis G. Birth weight and psychological distress at age 45-51 years: results from the Aberdeen Children of the 1950s cohort study. Br J Psychiatry 2005; 187: 21-8.

68 Burnett AC, Anderson PJ, Cheong J, Doyle LW, Davey CG, Wood SJ. Prevalence of psychiatric diagnoses in preterm and full-term children, adolescents and young adults: a meta-analysis. Psychol Med 2011; 41 2463-74.

69 Bellingham-Young DA, Adamson-Macedo EN. Foetal origins theory: links with adult depression and general self-efficacy. Neuro Endocrinol Lett 2003; 24: 412-6.

70 Frost AK, Reinherz HZ, Pakiz-Camras B, Giaconia RM, Lefkowitz ES. Risk factors for depressive symptoms in late adolescence: a longitudinal community study. Am J Orthopsychiatry 1999; 69: 370-81.

71 Boyle MH, Miskovic V, Van Lieshout R, Duncan L, Schmidt LA, Hoult L, et al. Psychopathology in young adults born at extremely low birth weight. Psychol Med 2011; 41: 1763-74. 